Jurnal Ilmu Budaya, Vol. 18, No. 1 Agustus Tahun 2021

\title{
ANALISIS SIMBOLIK STRUKTURAL BURUNG ENGGANG PADA MASYARAKAT DAYAK
}

\author{
Manarul Hidayat \\ Universitas Diponegoro, Semarang \\ Email: mangnawul@gmail.com
}

\begin{abstract}
Hornbills or Buceros sp. often used in various Dayak society activities, both of body parts and body illustrations. It shows that hornbills means very important for Dayak society. The importance and sacredness of hornbills can be seen through the structural symbolic concept of Levi-Strauss, which sees myth as starting from its structure before developing into a set of objects and phenomena in application. Hornbills are believed to play an important role in various aspects of life, through this found concept development that include objects and phenomena such as buildings, clothing, weapons, leadership and brotherhood, performances, and ceremonies.
\end{abstract}

Keywords: Symbol, Levi-Strauss, hornbills, Dayak society.

\section{Pendahuluan}

Burung enggang sangat erat

kaitannya dengan masyarakat Dayak.

Hal tersebut terlihat dari sering dijumpainya penyematan bagian tubuh burung enggang dalam perangkat hidup masyarakat Dayak. Selain itu, sering pula terdengar soal kesakralan burung enggang bagi masyarakat Dayak. Tetapi konsep-konsep yang merepresentasikan burung enggang pada tiap-tiap kelompok masyarakat
Dayak terkadang berbeda satu sama lain.

Kajian mengenai burung enggang menjadi penting mengingat kajian-kajian yang telah ada, pada umumnya tidak mengarahkan fokus pada burung enggang sebagai simbol. Beberapa yang benar-benar mengarahkan fokus pada burung enggang cenderung mengkaji populasi dan perburuan liar. Untuk itu, tulisan ini akan menelusuri mengapa burung engang begitu penting bagi masyarakat 
Dayak, serta menganalisis pola-pola yang menyertai konsep-konsep mengenai burung enggang.

\section{Masyarakat Dayak dan Sakralitas}

Pulau Kalimantan yang secara luas juga dikenal dengan nama Borneo, sebagian besar atau lebih tepatnya $73 \%$ wilayahnya termasuk dalam wilayah administrasi Indonesia. Borneo memiliki pengaruh yang besar terhadap ketersediaan oksigen dunia, mengingat disamping luasnya yang diperkirakan mencapai 74.000 .000 hektar, Borneo juga memiliki tingkat ketertutupan pohon yang tinggi. Dengan wilayah yang begitu luas ini, Borneo menjadi pusat keanekaragaman tumbuhan dunia. Setidaknya 10.000 jenis tumbuhan berbunga atau 5\% dari jenis tumbuhan berbunga yang ada di dunia, dan hampir separuh diantaranya merupakan jenis endemik Borneo (Soepadmo \& Wong dalam Noorhidayah, dkk. 2006: 96). Flora yang begitu kaya dalam jenis dan jumlah jelas mendorong beragamnya fauna di Borneo, termasuk berbagai satwa endemik Borneo.

Dayak merupakan suku yang secara umum dipahami sebagai penghuni hutan tropis Borneo, atau setidaknya sebagai suku yang mendominasi Borneo. Lebih jauh lagi, Dayak memiliki tujuh kelompok besar subsuku, yakni Punan, Iban, Apokayan, Ot' Danum, Ngaju, Klemantan, dan Murut, yang kembali terbagi menjadi 60 subsuku, hingga terbagi lagi menjadi 405 subsuku kecil yang penamaannya secara umum disesuaikan dengan nama anak sungai atau cabang sungai di wilayah mereka tinggal (Riwut, 2007: 266).

Kelestarian hutan Borneo yang kaya akan flora dan fauna pada hakikatnya tak terlepas dari prinsip yang dipegang erat oleh masyarakat Dayak mengenai hutan yang merawat, memelihara, dan juga membesarkan mereka. Itu mereka ungkapkan dengan istilah "Lunag Telang Otah Ine" yang berarti hutan adalah air susu ibu (Alfonsius, 2016: 233-234). Selain itu, 
Jurnal Ilmu Budaya, Vol. 18, No. 1 Agustus Tahun 2021

masyarakat Dayak juga membuat beberapa pantangan dan pengkudusan beberapa hal yang berkaitan dengan hutan dan segala isinya. Tanpa disadari, hal tersebut turut berperan dalam menjaga kelestarian hutan Borneo. Baik pantangan maupun pengkudusan sama-sama berada pada lingkaran mitos, yang oleh Peursen (1988: 37) dijelaskan sebagai sebuah cerita yang memberikan pedoman dan arah tertentu kepada sekelompok orang. Lebih lanjut, mitos memberikan arah kepada kelakuan manusiawi dan merupakan pedoman untuk kebijaksanaan manusia.

Salah satu pantangan yang berkaitan dengan flora dan fauna yang ada dalam kehidupan masyarakat Dayak dapat dilihat dari adanya konsep hutan terlarang atau dalam bahasa lokal disebut tana' ulen, yang dapat dijumpai pada masyarakat Dayak Kenyah di Kalimantan Timur (Samsoedin, dkk., 2010: 157). Penggunaan tana' ulen memiliki ketentuan khusus, mengingat karena terdapat nilai sejarah seperti kematian dan peristiwa besar, dengan disertai sanksi atau hukuman terhadap pelanggaran yang dilakukan. Pengecualian akan larangan penggunaan tana' ulen menurut Samsoedin dkk. (2010: 157) terjadi dalam kondisi dan keperluan tertentu, mengingat salah satu tujuan dari adanya konsep tana' ulen tersebut memang untuk menjaga cadangan keperluan masyarakat, serta untuk kepentingan kelestarian hasil produksi tertentu.

Sementara itu, salah satu yang berkaitan dengan pengkudusan melekat pada burung enggang. Burung enggang oleh masyarakat Dayak Kenyah diyakini sebagai wujud nenek moyang mereka ketika turun dari langit ke bumi. Bahasan mengenai burung enggang ini akan dibahas lebih jauh dalam bagian selanjutnya.

\section{Burung Enggang}

Burung enggang yang juga disebut dengan burung rangkong memiliki nama latin Buceros sp. atau Rhinoplax vigil (Darajati, dkk., 2016: 
152). Burung ini menurut Hernowo (1989: 22) termasuk dalam anggota suku Bucerotidae yang terkenal ketika bersarang dalam lubang pohon menyegel lubang dengan campuran tanah dan air liurnya.

Apa yang khas dari burung ini dapat tampak dari ciri fisiknya, yang pada bagian kepalanya memiliki paruh kokoh dengan ukuran yang cukup besar. Beberapa cabang dari jenis burung ini selain ada yang memiliki cula, ada pula yang memiliki gading. Cula dan gading tersebut disebut dengan casques atau balung yang pada umumnya hanya berupa rongga kosong, kecuali untuk burung enggang gading yang bagian depan balungnya padat, karena terbentuk dari keratin dan tidak memiliki pembuluh darah sehingga menjadi keras dan padat (Gamble dalam Adji, dkk., 2018: 6-7).

Selain kepala yang khas, burung enggang, terutama enggang gading, memiliki suara yang khas Menyerupai suara tertawa gila atau maniacal laugh dengan frekuensi antara $500-1500 \mathrm{~Hz}$, sehingga dapat terdengar sampai sejauh $3 \mathrm{~km}$. Kemungkinan, hal tersebut dilakukan untuk menarik perhatian individu lain dan juga menunjukkan kemampuan fisiknya (Haimoff dalam Adji, dkk., 2018: 7).

Persebaran burung enggang mencakup Myanmar bagian selatan, Semenanjung Malaysia, pulau Sumatera, dan pulau Kalimantan yang memiliki curah hujan tahunan kurang dari $3000 \mathrm{~mm}$. Lebih spesifik, burung enggang diketahui hidup di hutan primer yang hijau sepanjang tahun, khususnya di kaki pegunungan dengan topografi bergelombang, meskipun dapat pula ditemui di ketinggian 50 sampai 1500 mdpl dalam hutan bekas tebang pilih yang cenderung masih alami. Itu dikarenakan kebutuhan akan pangan berupa buah-buahan serta kecenderungannya untuk hidup jauh dari manusia (Adji, dkk., 2018: 7-8). Berdasarkan tutupan hutan tahun 2014, Adji, dkk. (2018: 8) memperkirakan ada 27,4 juta hektar lahan kering dan sekunder yang tersisa memberpotensi 
Jurnal Ilmu Budaya, Vol. 18, No. 1 Agustus Tahun 2021

menjadi habitat enggang gading di Sumatera dan Kalimantan.

Ciri fisik burung enggang yang pada bagian kepalanya memiliki semacam tanduk dan paruh besar membuatnya sangat berkharisma. Kehadirannya ditandai dengan kepakan sayapnya yang keras. Kehadirannya juga dapat menjadi indikator bagus atau tidaknya kondisi suatu ekosistem hutan (Hanum dan Dahlan, 2018: 35).

\section{Teori Simbolik Struktural} Berkaitan dengan kebudayaan dan simbol, Levi-Strauss (dalam Saifuddin, 2006: 202) berpendapat bahwa kebudayaan berskala kecil membangun keteraturan dunianya secara arbitrer atau manasuka, melalui simbol yang merepresentasi gagasan, nilai, dan suasana psikologi masyarakat. Keterkaitan antara keteraturan dengan simbol tersebut salah satu contohnya adalah aktivitas hewan yang dijadikan tanda suatu fenomena. Hewan dan fenomena yang diasosiasikan dapat berbeda, tetapi struktur atau hubungan yang terjalin dapat sama dengan struktur yang ada di kebudayaan lain.

Bagi Levi-Strauss, tak ada simbol yang arkaik. Jika simbol yang sama muncul pada beberapa kebudayaan, maka hal itu kemungkinan besar terjadi melalui difusi, atau karena unsur intrinsik dari objek-objek simbolik menunjukkan asosiasi yang sama dengan tradisi sejarah lain (Saifuddin, 2005: 203). Keberadaan mitos coba dibandingkan dengan keberadaan seni yang menurut Levi-Strauss (1966: 25-26) intinya sama-sama suatu tindakan penciptaan nan kreatif, tetapi dalam karya seni memiliki titik awal yang berupa sekumpulan objek dari fenomena yang kreasi estetiknya disatukan dengan mengungkap satu struktur yang sama, berbeda dengan mitos yang menggunakan struktur untuk menghasilkan objek dari sekumpulan fenomena. Dengan demikian, secara singkat dapat dikatakan bahwa seni berangkat dari himpunan objek dan fenomena (object + event) menuju 
penemuan (discovery) strukturnya, sedangkan mitos dimulai dari suatu struktur atau konsep utama yang kemudian mengonstruksi (constructs) himpunan objek dan fenomena (object + event).

Dari uraian tersebut dapat diketahui bahwa suatu mitos yang memuat simbol memiliki struktur pembentuk, baru dari situ mulai muncul pengembangan dalam hal penerapan simbol dari mitos tersebut. Itu semua tidak menutup kemungkinan untuk dapat diterapkan pada burung enggang yang dianggap suci atau dikuduskan oleh masyarakat Dayak.

\section{Pembahasan: Simbolisasi Burung Enggang}

Burung enggang atau rangkong bersama dengan naga menjadi simbol atau ornamen yang umum digunakan oleh masyarakat Dayak. Tidak mengherankan, mengingat dalam kosmologi tradisional yang ditemukan di seluruh Kalimantan, naga dianggap sebagai simbol dunia bawah, dan rangkong dianggap sebagai simbol dunia atas yang meliputi kehidupan, kesuburan, dan harmoni (Sellato, 1990: 37). Misalnya dalam masyarakat Dayak Aoheng, terdapat upacara pentas pertarungan antara kubu naga melawan kubu burung enggang, yang oleh Sellato (2002: 185) dikatakan bahwa kubu naga mewakili roh-roh yang telah tiada, sedangkan kubu burung enggang mewakili orang-orang yang masih hidup. Tentu ini hanya satu dari banyak simbolisasi burung enggang dalam masyarakat Dayak.

Kisah batang garing beredar di tengah masyarakat Dayak secara umum. Itu mengisahkan porakporandanya pohon yang bernama batang garing karena benturan perkelahian antara dua ekor burung enggang. Satu merupakan burung enggang jantan yang mengalami perputaran dan bergerak dari atas pohon ke bawah, sedangkan satu lainnya merupakan burung enggang betina yang mengalami perputaran dan bergerak dari bawah pohon ke atas. Keduanya merupakan jelmaan dari keris emas bertahtakan permata milik 
Jurnal Ilmu Budaya, Vol. 18, No. 1 Agustus Tahun 2021

Ranying Hatala, penguasa dunia atas yang bayang-bayangnya menguasai dunia bawah. Bagian bawah pohon batang garing ditandai dengan adanya guci air suci, sedangkan bagian puncaknya ditandai dengan matahari dan burung enggang itu sendiri. Berkaitan dengan benturan burung enggang, bagian-bagian dari batang garing yang berserakan karena benturan, kemudian memunculkan berbagai kehidupan, termasuk manusia laki-laki dan manusia perempuan (Santosa dan Djamari, 2015: 253-255). Secara singkat, burung enggang menjadi sosok kunci kelahiran manusia di alam dunia sebelum akhirnya diturunkan ke bumi. Keberadaan burung enggang dan matahari tepat di puncak batang garing menurut Kresandini (2016: 132) menjadi lambang atau simbol dari sumber segala kehidupan.

Masih berkaitan dengan simbol burung enggang yang berada di sisi atas, terdapat pakaian adat Dayak untuk laki-laki yang menyematkan bulu burung enggang. Itu dikenal dengan nama king baba, berasal dari kata king atau pakaian, dan $b a b a$ atau laki-laki, yang juga diidentikkan dengan pakaian perang. King baba memiliki penutup kepala yang terbuat dari serat kulit kayu, pada bagian itulah bulu burung enggang diselipkan (Darmadi, 2017: 103). Dahulu penutup kepala tersebut hanya digunakan ketika perang, tetapi sekarang menjadi bagian tak terpisahkan dari pertunjukan tari (Lenjau, dkk., 2012: 220). Begitu pula dengan pakaian adat Dayak untuk perempuan, hanya saja terdapat beberapa penambahan lain yang membuatnya terlihat lebih tertutup. Apabila ditelusuri lebih lanjut mengenai seperangkat pakaian adat Dayak yang identik dengan pakaian perang, maka akan ditemukan pula seperangkat alat perang yang berupa perisai dan pedang. Secara berurutan keduanya disebut dengan talawang dan mandau. Dalam alat perang tersebut dapat dijumpai simbol kehidupan berupa bentuk kepala burung enggang pada gagang mandau yang terbuat dari tanduk rusa, serta 
pada sarung mandau yang terkadang juga menjadikan bulu burung enggang sebagai hiasan. Pada gagang mandau simbol kepala burung enggang terkadang diganti dengan simbol kepala naga (Darmadi, 2017: 104). Senjata yang merupakan harapan untuk dapat bertahan hidup, terutama ketika perang, bersama dengan simbol kehidupan dalam bentuk bagian tubuh burung enggang, menjadi kesatuan yang mewakili harapan masyarakat Dayak seusai perang, yakni kehidupan.

Bangunan rumah masyarakat Dayak yang disebut lamin, juga memiliki dekorasi, baik dalam bentuk seni ukir, motif, dan lukisan. Itu secara singkat disebut dengan istilah kalung, yang tak luput dari pengaruh simbolsimbol yang berkaitan dengan burung enggang. Burung enggang termasuk dalam tujuh sumber figur kalung, yang menurut Kusumaningrum (2018: 28) meliputi tebengaang atau burung enggang, udo atau wajah manusia, kelunan atau manusia utuh, lenjau atau harimau, legunan atau naga, aso atau anjing, tanjau atau guci, serta munik atau pohon beringin. Lebih lanjut, apa yang berkaitan dengan burung enggang seperti gambar, patung, dan ukiran, dapat dijumpai di bagian atas belawing atau tugu wilayah komunitas, bagian atas berlubung umaq atau puncak atap rumah, bagian tengah ukiran awang ntiang atau dinding serambi lamin (Kusumaningrum, 2018: 31). Burung enggang dianggap asli Kalimantan, itu kemudian diyakini sebagai hewan leluhur, suci, pemersatu antarsuku Dayak di Kalimantan. Bagi mereka, bentuknya besar dan berparuh kuat, tetapi burung enggang memiliki karakter rendah hati, setia, dan berani. Melalui simbol burung enggang pada sudut-sudut lamin, diharapkan masyarakat Dayak dapat bersikap seperti burung enggang yang rendah hati, setia, dan berani (Kusumaningrum, 2018: 32).

Sedikit keluar dari rumah lamin atau rumah betang, pada masyarakat Dayak Ngaju di Kalimantan Tengah terdapat tiang pantar berjumlah 12 buah yang terletak di seberang lamin. Itu dibuat dari kayu ulin dengan 
Jurnal Ilmu Budaya, Vol. 18, No. 1 Agustus Tahun 2021

ketinggian 10-12 meter dan pada ujung

masing-masing tiang terdapat simbol burung enggang raja atau liak piau berupa ukiran. Menurut Widjaja dan Wardani (2016: 93) liak piau di puncak tiang pantar merupakan simbol penguasa alam langit. Lebih lanjut, tiang pantar tersebut juga dianggap sebagai jalan menuju surga dan simbol kepemimpinan dari leluhur di surga serta bukti leluhur tersebut telah ditiwah. Tiwah sendiri merupakan upacara penyimpanan tulang leluhur dalam sandung, semacam peti beratap yang disangga empat tiang dibawahnya. Burung enggang di bagian puncak sandung menjadi simbol kelengkapan kehidupan arwah orang yang telah meninggal, estetis dan prestisnya sandung merupakan penghormatan terakhir dari orang yang masih hidup untuk keluarga yang telah meninggal.

Artefak dengan ukiran burung enggang seringkali menjadi pusat pelaksanaan upacara berbagai kelompok masyarakat di Kalimantan. Menurut Langub (dalam Bennett, dkk.,
1997: 41) simbol-simbol burung enggang berupa ukiran dengan kerumitan tinggi diletakkan di tengah ketika upacara terhadap yang telah meninggal, dihadapkan ke hilir atau arah menuju laut serta menjadi penanda kuburan para bangsawan. Sedangkan untuk upacara terhadap yang masih hidup, ukiran burung enggang dihadapkan ke hulu sebagai simbol menuju sumber kehidupan. Simbol burung enggang berupa ukiran juga menjadi pusat salah satu upacara masyarakat Dayak Iban, yakni gawai kenyalang atau festival enggang yang dilakukan setiap 10 tahun sekali dan hanya diperbolehkan diselenggarakan setelah seseorang mendapat isyarat melalui mimpi (Bennett, dkk., 1997: 41). Dalam upacara ini, ukuran patung burung enggang yang dibuat berukuran cukup besar dan memiliki warna yang cerah, tetapi tidak terlampau kontras dan mencolok. Sedangkan mengenai motif ukiran, patung ini mengikuti apa yang tergambar dalam mimpi, itu semua dipersiapkan cukup lama dan bahkan dapat memakan waktu hingga 
satu tahun. Patung besar yang diukir dengan rupa penuh akan nuansa burung enggang menjadi simbol kekuatan atau spirit kehidupan, atas dasar itu maka selama proses persiapan upacara gawai kenyalang, masyarakat Dayak Iban memberikan persembahan berupa anggur, makanan, rokok, hingga uang, untuk patung enggang yang masih dalam proses pembuatan tersebut. Sedangkan ketika tiba waktunya untuk upacara maka persembahan untuk spirit kehidupan itu digantikan dengan babi dan ayam dengan jumlah yang banyak.

Dalam bidang pemerintahan, burung enggang cula menjadi burung kenegaraan bagi negara bagian Serawak, sementara itu di Kalimantan Barat burung enggang ditampilkan dalam simbol atau lambang pemerintah provinsi (Bennett, dkk., 1997: 41). Secara fisik, seperti kata Hanum dan Dahlan (2018: 37), burung enggang juga terdapat di halaman kantor Gubernur Kalimantan Timur dalam wujud patung. Pembuatannya yang menggunakan kayu secara penuh menghadirkan kesan kokoh dan menjulang tinggi pada sepasang patung burung enggang tersebut. Masih berkaitan dengan kepemimpinan, burung enggang dimaknai sebagai sebuah nilai kebaikan yang dipercayai masyarakat Dayak Kenyah mewakili kekuatan untuk melindungi atau menjaga kehidupan, itu menjadi sesuatu yang harus dimiliki oleh pemimpin mereka (Hanum dan Dahlan, 2018: 38. Burung enggang yang dianggap memiliki kemampuan untuk menjaga dan mengendalikan kehidupan dengan baik menjadi simbol sifat kepemimpinan ideal yang harus dijadikan teladan oleh seorang pemimpin.

\section{Orientasi}

Uraian pelibatan burung enggang dalam kehidupan masyarakat Dayak menunjukkan bahwa burung enggang bagi masyarakat Dayak telah menjadi suatu simbol dan memiliki makna tertentu. Gagasan mengenai nenek moyang yang turun dari dunia atas sebagai burung enggang 
merupakan mitos yang menjadi modus bagi masyarakat Dayak untuk menunjukkan jati diri bahwa mereka adalah manusia yang unggul, mereka adalah manusia dengan sebaik-baik manusia dengan beragam kebijakan dan kebaikan (Hanum dan Dahlan, 2018: 39).

Mitos yang berlaku dan dipercaya, bahkan kemudian dikembangan dalam berbagai objek dan fenomena oleh masyarakat Dayak, menunjukkan orientasi berpikir mereka yang masih terpengaruh dengan alam pikiran mistis, yang oleh Peursen (1988: 34) dikatakan masih membangun hubungan langsung dengan daya-daya alam yang serba rahasia.

\section{Struktur Mitos}

Berbagai hal yang memuat
simbol burung enggang bersama
dengan makna-makna yang menyertai
atau diwakili tersebut pada dasarnya
memiliki banyak kesamaan makna
yang menyertai. Atau dapat dikatakan
memiliki satu gagasan utama yang

kemudian dikembangkan dalam berbagai bentuk, baik ciptaan, gagasan, maupun tindakan.

Pentas pertarungan dengan kubu burung enggang yang mewakili orang-orang yang masih hidup, kisah batang garing yang bertutur bahwa kehidupan manusia disebabkan oleh dua ekor burung enggang, bulu dan ukiran enggang dalam pakaian dan senjata perang yang menyimpan harapan untuk dapat hidup setelah perang, motif burung enggang dalam rumah lamin yang menjadi simbol harmoni kehidupan, patung dan ukiran burung enggang dalam ritual sebagai simbol kekuatan atau spirit kehidupan, serta sifat saling menjaga dan melindungi burung enggang tehadap burung lain yang menjadi simbol sifat kepemimpinan ideal, merupakan bentuk-bentuk berbeda yang dikembangkan oleh masing-masing kelompok masyarakat Dayak dari suatu struktur mitos.

Sedangkan struktur pembentuk yang menarik satu garis kesamaan itu adalah gagasan bahwa burung enggang 
Jurnal Ilmu Budaya, Vol. 18, No. 1 Agustus Tahun 2021

merupakan sosok suci kunci

kehidupan. Burung enggang menjadi

sosok dari dunia atas yang memiliki

peran besar terhadap keberlangsungan

hidup umat manusia.

\section{Simpulan}

Beragam mitos yang begitu suci dan agung, serta simbolisasi yang begitu kuat dan baik mengenai burung enggang, disamping memberi batasan bagi masyarakat Dayak, juga menjadi pedoman bagi masyarakat Dayak untuk menjalani hidup.

Simbolik struktural pada hakikatnya memandang bahwa suatu mitos yang memuat simbol memiliki struktur pembentuk, yang kemudian dengan struktur pembentuk tersebut dibangunlah suatu himpunan objek dan fenomena. Berkaitan dengan hal tersebut, dapat diketahui bahwa pentingnya burung enggang bagi masyarakat Dayak berasal dari mitos mengenai burung enggang yang memegang peran penting dalam kehidupan. Dari situ dikembangkan dalam berbagai objek atau fenomena yang meliputi bangunan, pakaian, senjata, kepemimpinan dan persaudaraan, pementasan, hingga upacara.

\section{Daftar Pustaka}

Adji, B.D., dkk. (2018). Strategi dan Rencana Aksi Konservasi Rangkong Gading (Rhinoplax vigil) Indonesia 2018-2028. KLHK Republik Indonesia.

Alfonsius. (2016). "Masyarakat Adat Punan Dulau: Ditipu, Dimiskinkan, dan Diadu Domba" dalam Konflik Agraria Masyarakat Hukum Adat Atas Wilayahnya di Kawasan Hutan, hlm. 231-243. Komnas HAM Republik Indonesia.

Bennett, E.L., dkk. (1997). "Hornbills Buceros Spp. and Culture in Northern Borneo: Can They Continue to Co-Exist?" dalam Biological Conservation Vol. 82 No. 1 hlm. 41-46. Wildlife Conservation Society.

Darajati, W., dkk. (2016). Indonesian Biodiversity Strategy and Action Plan 2015-2020. Kementerian Perencanaan Pembangunan Nasional.

Darmadi, H. (2017). "Dayak and Their Daily Life" dalam Journal of Education, Teaching, and Learning, Vol. 2 No. $1 \mathrm{hlm}$. 101-105. Institut Keguruan dan 
Jurnal Ilmu Budaya, Vol. 18, No. 1 Agustus Tahun 2021

Ilmu Pengetahuan PGRI Pontianak.

Hanum, I.R. dan D. Dahlan. (2018). "Makna Mitos Cerita Burung Enggang di Kalimantan Timur" dalam CaLLs, Vol. 4 No. 1. Fakultas Ilmu Budaya Universitas Mulawarman Samarinda.

Hernowo, J.B. (1989). "Suatu Tinjauan terhadap Keanekaragaman Jenis Burung dan Peranannya di Hutan Lindung Bukit Soeharto Kalimantan Timur" dalam Media Konservasi, Vol. 2 No. 2 hlm. 19-32. Fakultas Kehutanan Institut Pertanian Bogor.

Kresandini, A. (2016). Estetika Batang Garing dalam Karya Perhiasan (Skripsi). Fakultas Seni Rupa Institut Seni Indonesia Yogyakarta.

Kusumaningrum, T.A. (2018). Jelajah Arsitektur Lamin Suku Dayak Kenyah. Jakarta: Badan Pengembangan dan Pembinaan Bahasa.

Lenjau, M., dkk. (2012). "Rattan and Bamboo: Handicraft of the Kenyah" dalam Plaited Arts from the Borneo Rainforest. Jakarta: The Lontar Foundation.

Levi-Strauss, C. (1966). The Savage Mind. Hertfordshire: The Garden City Press Limited.
Noorhidayah, dkk. (2006). "Potensi dan Keanekaragaman Tumbuhan Obat di Hutan Kalimantan dan Upaya Konservasinya" dalam Jurnal Analisis Kebijakan Kehutanan, Vol. 3 No. 2 hlm. 95-107. Fakultas Kehutanan Universitas Mulawarman Samarinda.

Peursen, C.A. van. (1988). Strategi Kebudayaan. Yogyakarta: Kanisius.

Riwut, T. (2007). Kalimantan Membangun. Yogyakarta: NR Publishing.

Saifuddin, A.F. (2005). Antropologi Kontemporer: Suatu Pengantar Kritis mengenai Paradigma. Jakarta: Kencana.

Samsoedin, I., dkk. (2010). "Konsep Tata Ruang dan Pengelolaan Lahan pada Masyarakat Dayak Kenyah di Kalimantan Timur" dalam Jurnal Analisis Kebijakan Kehutanan, Vol. 7 No. 2 hlm. 145-168.

Santosa, P. dan Djamari. (2016). "Kajian Historis Komparatif Cerita Batang Garing" dalam KANDAI, Vol. 11 No. $2 \mathrm{hlm}$. 248-265. Badan Pengembangan dan Pembinaan Bahasa.

Sellato, B. (1990). "Hornbills, Dragons, and Aoheng Dayak: Get Ready for 21st Century" dalam Voice of Nature, Vol. 20 hlm. 36-39. 
Jurnal Ilmu Budaya, Vol. 18, No. 1 Agustus Tahun 2021

Sellato, B. (2002). Innermost Borneo: Studies in Dayak Cultures. Singapore: Singapore University Press.

Widjaja, M.U. dan L.K. Wardani. (2016). "Makna Simbolik pada
Rumah Betang Toyoi Suku Dayak Ngaju di Kalimantan Tengah" dalam Dimensi Interior, Vol. 14 No. 2 hlm. 9099. Program Studi Desain Interior Universitas Kristen Petra

Surabaya. 